\title{
Subjective Cognitive Impairment Cohort (SCIENCe): study design and first results
}

Rosalinde E. R. Slot ${ }^{1 *+}$ D, Sander C. J. Verfaillie ${ }^{1+}$, Jozefien M. Overbeek ${ }^{1}$, Tessa Timmers ${ }^{1,4}$, Linda M. P. Wesselman ${ }^{1}$, Charlotte E. Teunissen², Annemiek Dols ${ }^{1,3}$, Femke H. Bouwman' ${ }^{1}$, Niels D. Prins' ${ }^{1}$, Frederik Barkhof ${ }^{4,5}$,

Adriaan A. Lammertsma ${ }^{4}$, Bart N. M. Van Berckel ${ }^{4}$, Philip Scheltens ${ }^{1}$, Sietske A. M. Sikkes ${ }^{1,6}$

and Wiesje M. Van der Flier ${ }^{1,6}$

\begin{abstract}
Background: We aimed to describe the Subjective Cognitive Impairment Cohort (SCIENCe) study design, to crosssectionally describe participant characteristics, and to evaluate the SCD-plus criteria.

Methods: The SCIENCe is a prospective cohort study of subjective cognitive decline (SCD) patients. Participants undergo extensive assessment, including cerebrospinal fluid collection and optional amyloid positron emission tomography scan, with annual follow-up. The primary outcome measure is clinical progression.

Results: Cross-sectional evaluation of the first 151 participants (age 64 \pm 8, 44\% female, Mini-Mental State Examination 29 \pm 2) showed that $28(25 \%)$ had preclinical Alzheimer's disease (AD) (amyloid status available $n=114$ $(75 \%)), 58(38 \%)$ had subthreshold psychiatry, and 65 (43\%) had neither. More severe subjective complaints were associated with worse objective performance. The SCD-plus criteria age $\geq 60$ (OR $7.7(95 \% \mathrm{Cl} 1.7-38.9)$ ) and apolipoprotein E (genotype) e4 (OR 4.8 (95\% Cl 1.6-15.0)) were associated with preclinical AD.

Conclusions: The SCIENCe study confirms that SCD is a heterogeneous group, with preclinical AD and subthreshold psychiatric features. We found a number of SCD-plus criteria to be associated with preclinical AD. Further inclusion and follow-up will address important questions related to SCD.
\end{abstract}

Keywords: Subjective cognitive decline, Preclinical Alzheimer's disease, Subthreshold psychiatry, SCD-plus criteria, Study design

\section{Background}

Alzheimer's disease (AD) develops gradually, and the first pathophysiological changes occur decades before a diagnosis of dementia $[1,2]$. Research interest is shifting to increasingly earlier stages, as the origin of $\mathrm{AD}$ and keys to treatment probably lie in the prevention of progression to fully fledged disease. Preclinical AD is defined as an asymptomatic stage of $\mathrm{AD}$, in which $\mathrm{AD}$ biomarkers are aberrant but clinical symptoms of objective cognitive decline are not present [3]. Subjective cognitive decline (SCD) refers to the experience of cognitive decline, without formal deficits on neuropsychological

\footnotetext{
*Correspondence: re.slot@vumc.nl

${ }^{\dagger}$ Rosalinde E. R. Slot and Sander C. J. Verfaillie contributed equally to this work.

${ }^{1}$ Alzheimer Center and Department of Neurology, Amsterdam Neuroscience, Amsterdam University Medical Centers, Vrije Universiteit, De Boelelaan 1118, $1081 \mathrm{HZ}$ Amsterdam, The Netherlands
}

testing, or any other neurological or psychiatric diagnosis explaining cognitive complaints [4]. The subjective experience of cognitive decline has been suggested to be one of the first symptoms of $\mathrm{AD}$, and patients with $\mathrm{SCD}$ have an increased risk of progression to $\mathrm{MCI}$ or dementia, especially when complaints are reported by both patient and informant [5-10]. In cognitively normal individuals with $\mathrm{SCD}$, biomarkers of $\mathrm{AD}$ can already be aberrant, such as low CSF amyoid-beta ${ }_{1-42}$, increased amyloid deposition on PET scans, and thinner medial temporal cortex [11-14]. However, the sequence of neurodegenerative changes eventually leading to $\mathrm{AD}$ may vary amongst individuals, and where to place $S C D$ in these pathological sequences remains to be elucidated.

It is difficult to clinically identify preclinical $\mathrm{AD}$ in cognitively healthy individuals experiencing memory complaints. To increase the likelihood of preclinical AD 
in individuals with SCD, the SCD-I Working Group has proposed the SCD-plus criteria [4]. These criteria include biomarkers such as APOE e4 carriership, but also patient specific features such as predominant self-perceived memory decline and feeling of worse memory performance than others of the same age. The SCD-plus criteria have been proposed to facilitate harmonizing SCD research, but they have not yet been prospectively validated.

Even though individuals with SCD on average have an increased risk of $\mathrm{AD}$, most individuals with $\mathrm{SCD}$ do not harbor Alzheimer pathology. Alternative potential explanations for the experience of memory complaints in cognitive healthy individuals include subthreshold symptoms of affective disorders, personality features, lifestyle factors, or systemic illnesses [15-17]. To evaluate the contribution of different factors related to SCD we have set up the memory clinic-based Subjective Cognitive Impairment Cohort (SCIENCe). In this ongoing cohort study we investigate individuals with SCD, without major psychiatric of neurological disorders. Here, we aimed to describe the SCIENCe study design, to cross-sectionally evaluate participants characteristics and factors related to cognitive complaints, and to evaluate the recently defined SCD-plus criteria as indicators of preclinical AD.

\section{Methods}

\section{Study design and work-up}

The Subjective Cognitive Impairment Cohort (SCIENCe) is a prospective cohort study including consecutive patients with SCD presenting at the Alzheimer Center of the VU University Medical Center Amsterdam. Here, we extensively describe the study design of the ongoing SCIENCe study. In addition, we report results based on a selection of cross-sectional data of the first 151 SCIENCe participants.

Inclusion criteria for the SCIENCe are a diagnosis of SCD (i.e., cognitive complaints and normal cognition) and age $\geq 45$ years. Exclusion criteria are MCI, dementia, major psychiatric disorder (i.e., current depression, personality disorders, schizophrenia), neurological diseases known to cause memory complaints (i.e., Parkinson's disease, epilepsy), HIV, abuse of alcohol or other substances, and language barrier.

All participants have been referred to the memory clinic by their general practitioner, and a neurologist or geriatrician in the case of a second opinion for evaluation of cognitive complaints. They receive standardized dementia screening at the memory clinic, including an interview with a neurologist, physical and neurological examination, neuropsychological assessment, as well as routine analyses of blood, CSF, and brain magnetic resonance imaging (MRI). After the standardized dementia screening, diagnoses are made in a multidisciplinary consensus meeting. Patients receive a label of SCD when cognitive functioning is normal and when there is no diagnosis of $\mathrm{MCI}$, dementia, or any other disease known to cause memory complaints [18]. When subtle symptoms of an underlying psychiatric diagnosis, such as depression, are suspected, patients are evaluated by an experienced psychiatrist to exclude possible formal psychiatric diagnoses as the cause of cognitive complaints.

Eligible patients with SCD are invited to participate in the SCIENCe. After inclusion in the SCIENCe, participants are invited for additional baseline assessments, which are described in detail in the following. After completion of baseline assessment, patients are invited for an annual follow-up visit consisting of clinical evaluation, extensive neuropsychological assessment, and questionnaires. At each follow-up visit, diagnoses are reevaluated under supervision of a neurologist. Main outcome measures are clinical progression to MCI or dementia and decline in cognitive functioning. If patients progress to $\mathrm{MCI}$ or dementia they are offered the possibility to return to a routine memory clinic follow-up. The SCIENCe work-up is visualized in Fig. 1.

The local medical ethics committee of the VU University Medical Center approved the study and all patients provide written informed consent for the use of their clinical data and biomaterial in research. All research is conducted in accordance with the Helsinki Declaration of 1975.

SCIENCe inclusion started in June 2014. In the first 2 years, 243 consecutive individuals aged 45 years or older received a diagnosis of $\mathrm{SCD}$, of which 56 were not eligible for participation and 36 individuals were not interested in participation (Fig. 2). This led to inclusion of 151 individuals in the SCIENCe until the start of data analysis for the current report. In this cross-sectional report of SCIENCE baseline findings, we evaluate these first 151 participants. Further inclusion in the SCIENCe and follow-up of participants is currently ongoing.

\section{Questionnaires}

Additional file 1: Table S1 provides a detailed overview of the questionnaires used to evaluate SCD, mental health, instrumental activities of daily living, and lifestyle (i.e., dietary intake, and physical and cognitive activity).

\section{Subjective cognitive decline}

We use the Dutch translation of the Cognitive Change Index-self (CCI-S) and Cognitive Change Index-informant report (CCI-I) (20 questions, range 0-80) to assess cognitive function compared to 5 years ago [13]. Higher scores reflect worse subjective cognitive function. The CCI cutoff value for significant cognitive complaints is set at 16/80 [19]. In addition, we use the Subjective Cognitive Functioning (SCF) questionnaire (four 


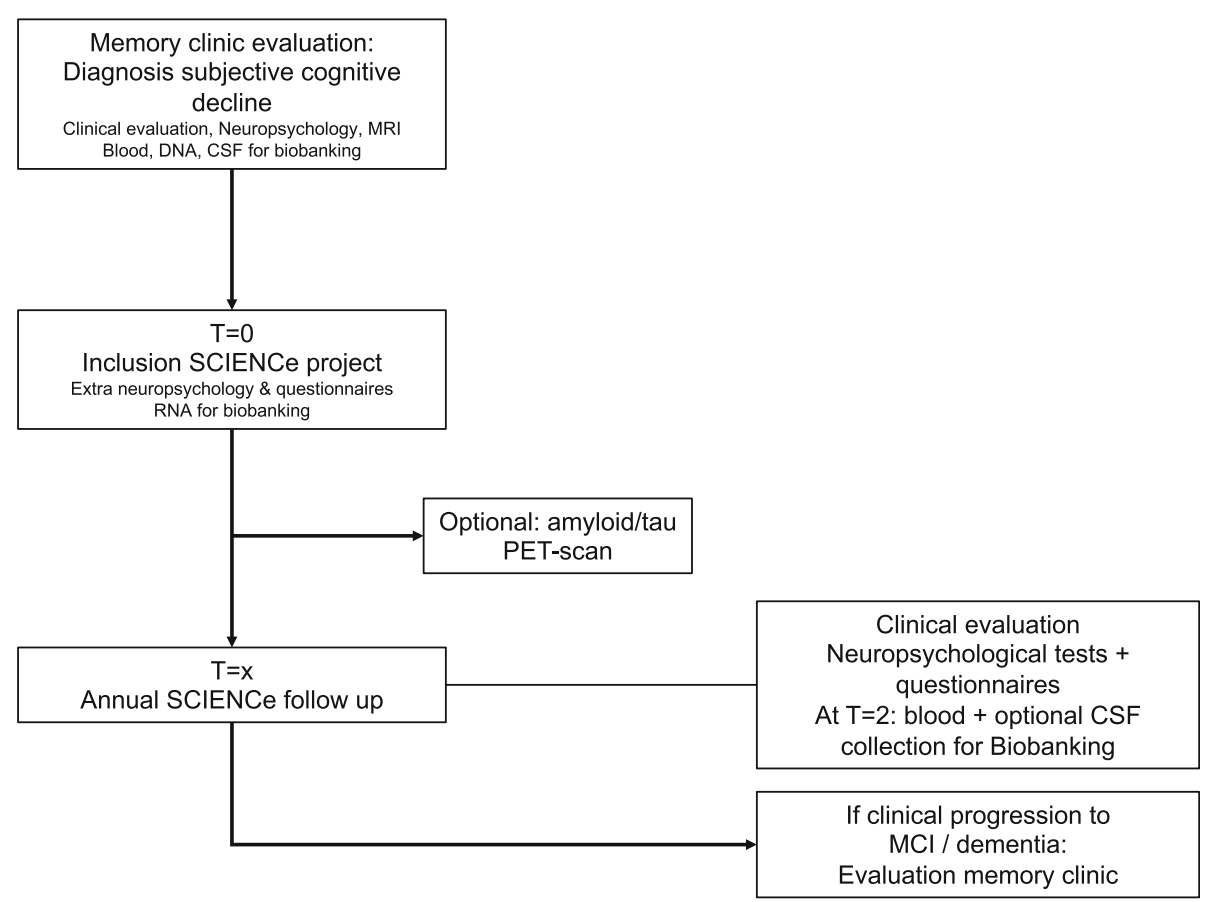

Fig. 1 SCIENCe work-up. SCIENCe work-up at baseline and annual follow-up study visits. Primary outcome is clinical progression to MCl or dementia. CSF cerebrospinal fluid, MCI mild cognitive impairment, MRI magnetic resonance imaging, PET positron emission tomography, SCIENCe Subjective Cognitive Impairment Cohort

questions, range -12 to +12 ) to assess self-experienced cognitive decline over a 1-year time period [20]. A SCF score below 0 represents decline.

\section{Psychiatric symptoms}

We use the following questionnaires to evaluate psychiatric symptoms: depressive symptoms, CES-D [21]; anxiety, HADS-A [22]; neuroticism, NPV neuroticism subscale [23, 24], low mastery, Pearlin Mastery scale [25]; distress and somatization (defined as nonspecific physical complaints), 4-DKL distress and somatization subscales [23]; and quality of life, EuroQol [26]. For all psychiatric and quality-of-life questionnaires, higher scores reflect worse performance. See Additional file 1: Table S1 for cutoff values of the questionnaires.

\section{Neuropsychological evaluation}

All participants received a comprehensive standardized neuropsychological assessment at the regular memory clinic evaluation [18]. As part of the SCIENCe baseline investigation we perform an additional neuropsychological assessment (median time between assessments 37 days) evaluating cognitive domains: memory, language, attention, executive and visuospatial functioning, with a special emphasis on memory; see Additional file 1: Table S1 for an overview of the complete SCIENCe test battery. This test battery is repeated at follow up.
In this paper we report on a subset of the neuropsychological assessment. We used the MMSE to assess global cognition [27]. For the memory domain we used the Dutch version of the Rey Auditory Verbal Learning Test (RAVLT) - direct recall (five trials summed) and delayed recall and cued recall (both $>20 \mathrm{~min}$ ) [28]. We used Trail Making Test (TMT) A to evaluate attention, and TMT B to evaluate executive functioning [29]. To evaluate language functioning we used categorical animal fluency.

\section{Magnetic resonance imaging}

Structural MRI is acquired during the diagnostic visit to the memory clinic using a MR750 (General Electric, Milwaukee, WI, USA), Philips PET/MR (Philips Medical Systems, Best, the Netherlands), or Toshiba Titan (Toshiba Medical Systems, Otawara, Japan). The MRI protocol includes isotropic 3D T1-weighted and Fluid Attenuated Inversion Recovery (FLAIR) T2-weighted, and Susceptibility Weighted Imaging (SWI). T1-weighted images are used to estimate hippocampal and normalized brain volumes (NBV) using FIRST and SIENAX with optimized settings (FMRIB software library v5, Oxford, UK) $[30,31]$ derived from a tissue-type segmentation, using optimized parameter settings and a scaling factor to normalize for skull size [31]. All registrations are visually inspected for artifacts. All images are read by a neuroradiologist in a standardized fashion. The severity of 


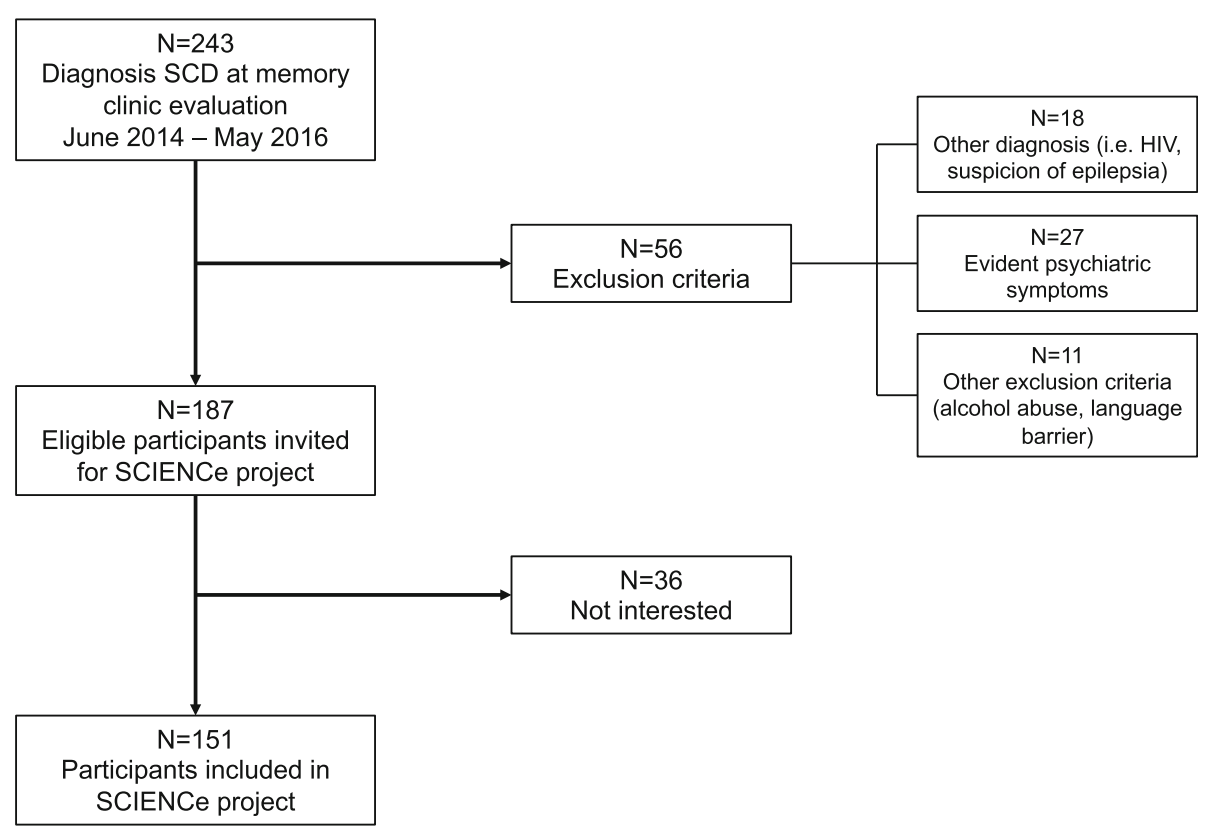

Fig. 2 Flow chart of study inclusion. Flow-chart of inclusion of SCIENCe participants evaluated in current report $(n=151)$. Further inclusion and follow-up currently ongoing. SCD subjective cognitive decline, SCIENCe Subjective Cognitive Impairment Cohort

white-matter hyperintensities (WMHs) using the Fazekas scale is determined on the FLAIR sequence (possible range 0-3), and dichotomized into absent $(0-1)$ or present $(2-3)$. Lacunes are defined as deep lesions (3-15 mm) with CSF-like signal on all sequences. Lacunes are scored as absent or present ( $\geq 1$ lacune). Microbleeds are defined as small dot-like hypointense lesions on T2-weighted MRI. Microbleed count is dichotomized into absent or present ( $\geq 1$ microbleed). Here, we present baseline normalized brain volume, bilateral hippocampal volume, WMHs, lacunes, and microbleeds. MRI data within 1 year from SCIENCe inclusion were available for 116 (77\%) participants.

\section{Biomaterial for biobanking}

Blood (serum and plasma), DNA, and CSF are obtained and stored in our biobank at the department of Clinical Chemistry of the VU University Medical Center Amsterdam, according to international consensus standard operation procedures [32, 33].

\section{Blood and DNA}

Venous blood (2-6 ml clotted blood for serum and $6 \mathrm{ml}$ EDTA blood for plasma) is processed and stored according to international consensus standard operation procedures. EDTA whole blood $(2-4 \mathrm{ml})$ is collected for DNA extraction. After collection, plasma and serum samples are centrifuged at room temperature at $2000 \times g$ (minimum $1800 \times g$, maximum $2200 \times g$ ), aliquoted into 0.5 - $\mathrm{ml}$ vials, and stored at $-80^{\circ} \mathrm{C}$.

\section{RNA}

After SCIENCe inclusion, one PAXgene Blood RNA tube (PreAnalytiX; Qiagen, Venlo, the Netherlands) is collected and without aliquoting stored in the biobank at $-80^{\circ} \mathrm{C}$.

\section{CSF}

CSF is collected from nonfasted subjects. CSF is obtained by lumbar puncture between the L3/L4 or L4/L5 intervertebral space by a 25 -gauge needle and collected in polypropylene tubes.

After collection, CSF and plasma samples are centrifuged at room temperature at $2000 \times g$ (minimum $1800 \times g$, maximum $2200 \times g$ ), aliquotted into $0.5-\mathrm{ml}$ vials, and stored at $-80{ }^{\circ} \mathrm{C}$. A maximum of $2 \mathrm{~h}$ is allowed between collection and freezing [32,33].

\section{$A P O E$ genotyping}

$A P O E$ genotyping is performed after automated genomic DNA isolation from 2-4 ml EDTA blood. It is subjected to PCR, checked for size and quantity using a QIAxcel DNA Fast Analysis kit (Qiagen), and sequenced using Sanger sequencing on an ABI130XL. Here, APOE status was available for 144 (95\%) individuals. Subjects with one or two $\varepsilon 4$ alleles were classified as $A P O E$ e4 carriers.

\section{Cerebrospinal fluid markers}

From the total amount of collected CSF at memory clinic visit, $2.5 \mathrm{ml}$ is used for routine analyses, including leukocyte count, erythrocyte count, glucose concentration, and total amount of protein, and frozen at $-20{ }^{\circ} \mathrm{C}$ 
until further analysis of Alzheimer biomarkers. Amyloid-beta $_{1-42}$ (A $\left.\beta 42\right)$, tau, and tau phosphorylated threonine 181 (ptau) levels are measured using ELISA (Innogenetics-Fujirebio, Ghent, Belgium) at the Neurochemistry Laboratory [34]. Our center cutoff value for CSF A 42 indicating AD pathology is $<640 \mu \mathrm{g} / \mathrm{L}$ [35].

\section{Positron emission tomography scans}

All participants are invited to participate additionally in an amyloid PET study. Patients are scanned with either $\left[{ }^{18} \mathrm{~F}\right]$ florbetapir (Amyvid) or $\left[{ }^{18} \mathrm{~F}\right]$ florbetaben (Neuraceg) radiotracer. Before scanning, one cannula is inserted for tracer infusion. For florbetapir, 90-min dynamic PET emission scans (PET/CT Ingenuity TF or Gemini TF; Philips Medical Systems) are acquired immediately following bolus injection of approximately $370 \mathrm{MBq}\left[{ }^{18} \mathrm{~F}\right]$ florbetapir. For florbetaben, 20-min static PET emission scans (PET/ MR; Philips Medical Systems) are acquired 90 min after a bolus injection of approximately $250 \mathrm{MBq}\left[{ }^{18} \mathrm{~F}\right]$ florbetaben. All PET scans are visually read by a nuclear medicine physician. For the current manuscript, PET scans were available for 105/151 (69\%) participants.

\section{Amyloid status}

Information on amyloid status was available for 114 (75\%) participants (PET only $n=38$ (25\% of total), CSF only $n=$ 9 (6\%), CSF and PET $n=67$ (44\%)). Amyloid status could be determined if: CSF and/or amyloid PET was performed within 1 year of baseline visit; or if repeated amyloid measurements were concordant before and after baseline (i.e., both negative or both positive). There were seven cases with discordant PET/CSF results. In all seven cases, CSF A 342 was above the cutoff value of $640 \mu \mathrm{g} / \mathrm{L}$ (range 645$881 \mu \mathrm{g} / \mathrm{L}$ ), but amyloid PET was positive; we considered these cases as amyloid positive.

\section{Categorization of participants according to concomitant symptoms}

In this cross-sectional report of SCIENCE baseline findings, we categorized SCIENCe participants into categories based on the presence of preclinical $A D$ and/or subthreshold psychiatry, as potential factors associated with SCD [4].

\section{Preclinical $A D$}

Amyloid-positive individuals based on PET and/or CSF amyloid (see Amyloid status) were classified as preclinical AD.

\section{Subthreshold psychiatry}

Individuals with one or more questionnaires indicative of subthreshold symptoms of depression, anxiety, neuroticism, low mastery, distress, or somatization were classified as subthreshold psychiatry (see Additional file 1:
Table S1 for an overview of questionnaires and cutoff values used). Fulfillment of clinical criteria for a formal psychiatric diagnosis was an exclusion criterion for the SCIENCe, hence psychiatric symptoms measured with the questionnaires were subthreshold. When participants were amyloid positive but also had subthreshold psychiatric symptoms they were classified in the preclinical $\mathrm{AD}$ group. Amyloid status was not available in the subthreshold psychiatry category for 21 of 58 cases (36\%).

\section{Undetermined}

When participants were neither amyloid positive or there was no indication of subthreshold psychiatric symptoms, they were classified in the undetermined category. Amyloid status was not available in the undetermined category for 16 of 65 patients (25\%).

\section{SCD-plus criteria}

The SCD-plus criteria refer to specific features of SCD associated with an increased likelihood of preclinical AD [4]. The SCD-plus criteria are: (1) subjective decline in memory, rather than other domains of cognition (in our study defined as 'memory decline present' as evaluated in the SCF questionnaire); (2) onset of SCD within the last 5 years; (3) age at onset of $S C D \geq 60$ years; (4) concerns (worries) associated with SCD; (5) feeling of worse performance than peers (here operationalized with a specific question in the CCI questionnaire); (6) confirmation of perceived cognitive decline by an informant (here operationalized as a CCI informant report score above cutoff value of significant symptoms (>16)); and (7) APOE e4 carriership. We evaluated the SCD-plus criteria with the exception of criterion worries associated with SCD (4), which we considered present in all participants since they all visited our memory clinic because of cognitive complaints.

\section{Statistical analyses}

Data were analyzed using IBM SPSS Statistics, version 22 (IBM, Armonk, NY, USA). We assessed baseline features of the study population and evaluated differences between participant categories (preclinical AD, subthreshold psychiatry, or undetermined), using chi-squared tests or ANOVA, adjusted for age and gender, as appropriate, followed by post-hoc analyses. We used univariate linear regression analyses to assess associations between cognitive complaints (CCI-S, CCI-I, and SCF) and neuropsychological test scores, adjusted for age and gender.

Furthermore, we evaluated the prevalence of the SCD-plus criteria in participants with available amyloid status. Subsequently, we used logistic regression to investigate the associations of SCD-plus criteria with the risk of preclinical AD. First, we performed univariate models with each SCD-plus criterion 
separately (model 1 ). Then, we constructed model 2 as a multivariate model with backward stepwise selection with the six available SCD-plus criteria. We considered $p<0.05$ significant.

\section{Results}

\section{Baseline demographics}

At baseline the first 151 SCIENCe participants were on average $64 \pm 8$ years old (range $45-84$ years), and 67 (44\%) were female (Table 1). Participants received on average 12 \pm 3 years of education, and $76(54 \%)$ had a family history of dementia. Fifty-five participants (38\%) were APOE e4 positive (APOE e4 status available for $n=144(95 \%)$ ).

\section{Self-report of SCD}

We cross-sectionally assessed report of subjective cognitive functioning compared to 1 year ago (SCF self-report) and 5 years ago (CCI; both self-report and informant report; Table 1). Over the preceding 5-year time period 146 (97\%) participants reported cognitive decline (CCI-S), of which $89(60 \%)$ reported substantial decline. Over a 1-year time period (SCF), 104 (69\%) participants reported substantial cognitive decline. Adjusted for age, gender, and education, higher CCI-S was associated with worse SCF (standardized $\beta=-0.40, p<0.001$ ), and CCI-S was also associated with CCI-I $(s \beta=0.48, p<0.001$; Table 2). In addition, we found that higher self-report of subjective cognitive functioning (CCI-S and SCF) was associated with worse quality of life ( $\mathrm{s} \beta=-0.34$; $\mathrm{s} \beta=0.25$; both $p<0.05$ ). Furthermore, higher CCI (both self and informant) were associated with worse performance on cognitive tests (Table 2), while there were no associations between SCF and objective measures of cognition.

\section{SCD groups}

When we attempted to categorize participants according to the presence of preclinical $\mathrm{AD}$ and/or subthreshold psychiatric symptoms, we found 28 individuals $(25 \%$ of 114 participants with known amyloid status, and $18 \%$ of total sample) with preclinical AD. Higher age was associated with an increased risk of preclinical $\mathrm{AD}$ (odds ratio 1.14 (95\% CI 1.06-1.22); Fig. 3).

In the remaining sample, 58 (38\%) participants reported subthreshold psychiatric symptoms on one or more questionnaires. Of these participants, $21 \%$ had subthreshold symptoms in the affective cluster, for example depressive (11\%) and/or anxiety (13\%) symptoms. Roughly one out of three (31\%) had distress and/or somatization-related symptoms, and in $27 \%$ there was an indication of symptoms of neuroticism and/or low mastery. In addition, 8 of 28 (29\%) patients in the preclinical AD category also had subthreshold psychiatric symptoms.
The largest group of SCD $(n=65(43 \%))$ had neither evidence of amyloid nor of subthreshold psychiatric symptoms (undetermined category).

Comparing these three SCD groups, participants with preclinical $\mathrm{AD}$ were on average older than individuals in the subthreshold psychiatry $(p<0.001$; Table 1$)$ and undetermined category $(p<0.05)$. Participants with preclinical AD more frequently had a family history of dementia than subthreshold psychiatry, and they were APOE e4 carriers more frequently than the other two groups (all $p<0.01$ ). There were no differences in gender, education, or MRI measures between groups. Self-reported cognitive decline was higher in participants with subthreshold psychiatry than in the undetermined category, with preclinical AD in between (both $p<0.01$ ). Results were similar for informant-reported cognitive decline. Reported quality of life was lower in the subthreshold psychiatry group than in the undetermined category $(p=0.002)$, with preclinical $\mathrm{AD}$ in between. Comparing objective cognitive performance between groups, the group with subthreshold psychiatry performed worse on the TMT-A compared to preclinical $\mathrm{AD}$ and undetermined groups (all $p<0.05$ ). Also, subthreshold psychiatry performed worse on the TMT-B than the undetermined group $(p<0.05)$, but there were no differences in other cognitive tests, see Table 1.

\section{SCD-plus criteria and the risk of preclinical AD}

Univariate logistic regression analyses showed that SCD-plus criteria 'age $\geq 60$ ' (OR 7.7 (95\% CI 1.7-34.6)) and 'APOE e4 carriership' (OR 5.0 (2.0-12.8)) were associated with an increased risk of preclinical AD (Fig. 4), whereas 'memory specific decline', 'onset of complaints within 5 years', 'worse performance than other of the same age', and 'informant reports decline' were not (Table 3). In a multivariate stepwise model, APOE e4 carriership (OR $6.2(1.7-22.2)$ ) and age $\geq 60$ (OR 3.8 $(1.7-20.4))$ remained independently associated with preclinical AD.

\section{Discussion}

The SCIENCe project aims to investigate factors potentially related to SCD. Cross-sectional evaluation of the first 151 cognitively normal participants with SCD revealed a heterogeneous group, with preclinical $A D$ in one fifth to one quarter of participants, and subthreshold psychiatric symptoms in more than one third of participants, while the largest group of participants did not have evidence of either. We found that higher report of SCD was associated with lower quality of life, and also with worse cognitive performance. Finally, the SCD-plus criteria age $\geq 60$ and APOE e4 carriership were associated with an increased risk of preclinical $\mathrm{AD}$, defined by amyloid positivity on either PET or in CSF. 
Table 1 Demographic features of the study population

\begin{tabular}{|c|c|c|c|c|c|c|c|c|}
\hline & & $n$ & $\begin{array}{l}\text { Total group } \\
(N=151)\end{array}$ & & $\begin{array}{l}\text { Preclinical AD } \\
(n=28)\end{array}$ & $\begin{array}{l}\text { Subthreshold } \\
\text { psychiatry }(n=58)\end{array}$ & $\begin{array}{l}\text { Undetermined } \\
(n=65)\end{array}$ & $p$ \\
\hline \multirow[t]{6}{*}{ Demographics } & Age & 151 & $64 \pm 8$ & & $69 \pm 7^{b}$ & $62 \pm 8^{a}$ & $64 \pm 8^{a}$ & 0.002 \\
\hline & Gender, female & 151 & $67(44)$ & & $11(39)$ & $27(47)$ & $29(45)$ & NS \\
\hline & Education (years) & 148 & $12 \pm 3$ & & $13 \pm 3$ & $12 \pm 3$ & $12 \pm 2$ & NS \\
\hline & Family history dementia & 140 & $76(54)$ & & $18(75)^{b}$ & $20(36)^{\mathrm{a}}$ & $38(62)^{b}$ & 0.002 \\
\hline & APOE e4 carrier & 144 & $55(38)$ & & $17(65)^{b}$ & $17(30)^{\mathrm{a}}$ & $21(34)^{a}$ & 0.007 \\
\hline & & & & $\begin{array}{l}n \text { above } \\
\text { cutoff value }\end{array}$ & & & & \\
\hline \multirow[t]{3}{*}{$\begin{array}{l}\text { Subjective cognitive } \\
\text { decline }\end{array}$} & $\begin{array}{l}\text { SCF (1-year change) self- } \\
\text { report }\end{array}$ & 150 & $-1.65 \pm 2.98$ & $104(69)$ & $-2.0 \pm 2.3$ & $-2.4 \pm 3.2$ & $-0.8 \pm 2.9^{b}$ & 0.004 \\
\hline & $\begin{array}{l}\mathrm{CCl} \text { (5-year change) self- } \\
\text { report }^{\complement}\end{array}$ & 148 & $21.8 \pm 14.3$ & $89(60)$ & $21.4 \pm 13.2^{b}$ & $27.8 \pm 15.2^{\mathrm{a}}$ & $16.7 \pm 11.8^{b}$ & 0.000 \\
\hline & $\begin{array}{l}\text { CCI (5-year change) } \\
\text { informant }^{\complement}\end{array}$ & 127 & $19.4 \pm 17.1$ & $62(49)$ & $19.8 \pm 13.9^{b}$ & $26.4 \pm 19.1^{\mathrm{a}}$ & $13.8 \pm 14.8^{b}$ & 0.000 \\
\hline \multirow{7}{*}{$\begin{array}{l}\text { Mental health } \\
\text { questionnaires }\end{array}$} & Quality of Life & 149 & $76 \pm 15$ & & $79 \pm 12$ & $71 \pm 16$ & $80 \pm 15^{b}$ & 0.012 \\
\hline & Depressive symptoms $^{c}$ & 150 & $8.3 \pm 6.4$ & $17(11)$ & $7.0 \pm 4.6$ & $12.1 \pm 7.3$ & $5.5 \pm 4.1$ & 0.000 \\
\hline & Anxiety $^{c}$ & 150 & $4.0 \pm 2.9$ & $13(13)$ & $4.1 \pm 2.6$ & $5.6 \pm 3.1$ & $2.4 \pm 1.9$ & 0.000 \\
\hline & Distress $^{c}$ & 150 & $6.7 \pm 5.9$ & $34(22)$ & $4.6 \pm 4.6$ & $11.1 \pm 6.3$ & $3.6 \pm 2.9$ & 0.000 \\
\hline & Somatization ${ }^{c}$ & 151 & $6.3 \pm 5.3$ & $31(21)$ & $4.6 \pm 3.7$ & $10.3 \pm 5.7$ & $3.5 \pm 2.8$ & 0.000 \\
\hline & Neuroticism ${ }^{c}$ & 145 & $6.6 \pm 5.5$ & & $5.2 \pm 3.8$ & $10.1 \pm 6.4$ & $4.0 \pm 2.8$ & 0.000 \\
\hline & Low mastery ${ }^{c}$ & 140 & $10.5 \pm 3.9$ & & $10.0 \pm 3.0$ & $12.8 \pm 4.0$ & $8.5 \pm 2.7$ & 0.000 \\
\hline Cognition & MMSE & 151 & $28.6 \pm 1.2$ & & $28.4 \pm 1.3$ & $28.5 \pm 1.2$ & $28.9 \pm 1.2$ & 0.031 \\
\hline \multirow[t]{3}{*}{ Memory domain } & RAVLT immediate recall & 149 & $44.3 \pm 9.0$ & & $43.4 \pm 8.7$ & $44.0 \pm 9.0$ & $44.6 \pm 9.2$ & NS \\
\hline & RAVLT delayed recall & 149 & $9.0 \pm 2.9$ & & $8.5 \pm 2.9$ & $9.1 \pm 3.0$ & $9.2 \pm 2.9$ & NS \\
\hline & RAVLT cued recall & 149 & $28.7 \pm 1.6$ & & $28.7 \pm 1.5$ & $28.5 \pm 2.3$ & $28.8 \pm 1.4$ & NS \\
\hline Attention & TMT A & 148 & $34.4 \pm 12.8$ & & $33.4 \pm 12.2^{b}$ & $37.5 \pm 14.9^{a}$ & $32.1 \pm 10.5^{b}$ & 0.014 \\
\hline $\begin{array}{l}\text { Executive } \\
\text { functioning }\end{array}$ & TMT $B^{c}$ & 147 & $82.1 \pm 33.2$ & & $79.5 \pm 28.9$ & $89.8 \pm 41.0$ & $76.2 \pm 25.8^{b}$ & 0.058 \\
\hline Language & Animal fluency & 147 & $23.2 \pm 5.2$ & & $22.8 \pm 4.9$ & $23.1 \pm 5.1$ & $23.5 \pm 5.6$ & NS \\
\hline \multirow[t]{5}{*}{ MRI } & $\begin{array}{l}\text { Normalized brain volume } \\
(\mathrm{ml})\end{array}$ & 116 & $1399 \pm 79$ & & $1366 \pm 75$ & $1407 \pm 81$ & $1406 \pm 79$ & NS \\
\hline & $\begin{array}{l}\text { Bilateral hippocampal } \\
\text { volume (ml) }\end{array}$ & 116 & $9.9 \pm 1.3$ & & $10.0 \pm 1.4$ & $9.9 \pm 1.3$ & $9.8 \pm 1.1$ & NS \\
\hline & $\begin{array}{l}\text { White-matter } \\
\text { hyperintensities (present) }\end{array}$ & 116 & $10(9)$ & & $2(9)$ & $2(4)$ & $6(13)$ & NS \\
\hline & Lacunes (>0) & 115 & $3(3)$ & & $1(4)$ & $2(5)$ & $0(0)$ & NS \\
\hline & Microbleeds present $(>0)$ & 112 & $19(17)$ & & $7(30)$ & $4(10)$ & $8(17)$ & NS \\
\hline
\end{tabular}

Unadjusted results presented as mean \pm standard deviation or $n$ (\%). Differences between groups assessed using age, gender, and education-adjusted analysis of variance or chi-squared tests

$A D$ Alzheimer's disease, $A P O E$ apolipoprotein E genotype, $C C l$ cognitive change index, MMSE Mini-Mental State Examination, MRI magnetic resonance imaging,

NS not significant, RAVLT Rey Auditory Verbal Learning Test, SCF subjective cognitive functioning, TMT Trail Making Test

${ }^{a} p<0.05$ difference with preclinical AD

${ }^{\mathrm{b}} p<0.05$ difference with subthreshold psychiatry

'Higher scores reflect worse performance or more symptoms

We measured the degree of subjective complaints with the short SCF questionnaire and used the CCI for more in-depth evaluation $[13,20]$. Almost all participants reported cognitive decline, which seems substantially higher than in the general population [36], and could be a reflection of our cohort with individuals actively seeking medical evaluation in a memory clinic because of these cognitive complaints. A small minority of $3 \%$ did not report any complaints, potentially explained by the fact that participants filled in the questionnaires after a thorough memory clinic evaluation, with reassurance of normal cognitive functioning. 
Table 2 Associations between subjective and objective cognitive measures

\begin{tabular}{llll}
\hline & SCF & CCl-self & CCl-informant \\
\hline CCl-self $^{\mathrm{a}}$ & $-0.39^{* *}$ & & \\
CCl-informant $^{\mathrm{a}}$ & $-0.19^{*}$ & $0.49^{* *}$ & \\
EuroQol & $0.25^{*}$ & $-0.33^{* *}$ & -0.15 \\
MMSE & 0.14 & $-0.30^{* *}$ & -0.10 \\
RAVLT immediate recall & 0.01 & $-0.21^{*}$ & -0.15 \\
RAVLT delayed recall & 0.03 & -0.16 & -0.04 \\
RAVLT cued recall & -0.12 & $-0.23^{*}$ & $-0.17^{*}$ \\
TMT A $^{\text {a }}$ & -0.06 & 0.12 & 0.17 \\
TMT B $^{\text {a }}$ & -0.17 & $0.23^{*}$ & $0.26^{*}$ \\
Animal fluency & 0.15 & -0.15 & -0.14 \\
\hline
\end{tabular}

Associations presented as standardized $\beta$, adjusted for age, gender, and education SCF subjective cognitive functioning (lower scores indicate more complaints), $\mathrm{CCl}$ cognitive change index (higher scores indicate more complaints), MMSE Mini-Mental State Examination, RAVLT Rey Auditory Verbal Learning Test, TMT Trail Making Test

${ }^{*} p<0.05$

${ }^{* *} p<0.001$

${ }^{\mathrm{a}}$ Higher scores reflect worse cognitive performance

We found that higher report of cognitive complaints was associated with worse quality of life, suggesting that subjective complaints have a negative effect on a general feeling of wellbeing. On the other hand, we cannot exclude reverse causality, as worse quality of life may also affect the subjective appreciation of one's (cognitive) abilities [37]. Furthermore, we found that higher report of cognitive complaints on the CCI (both self and informant) was associated with worse objective cognitive performance in our cognitive normal sample with SCD,

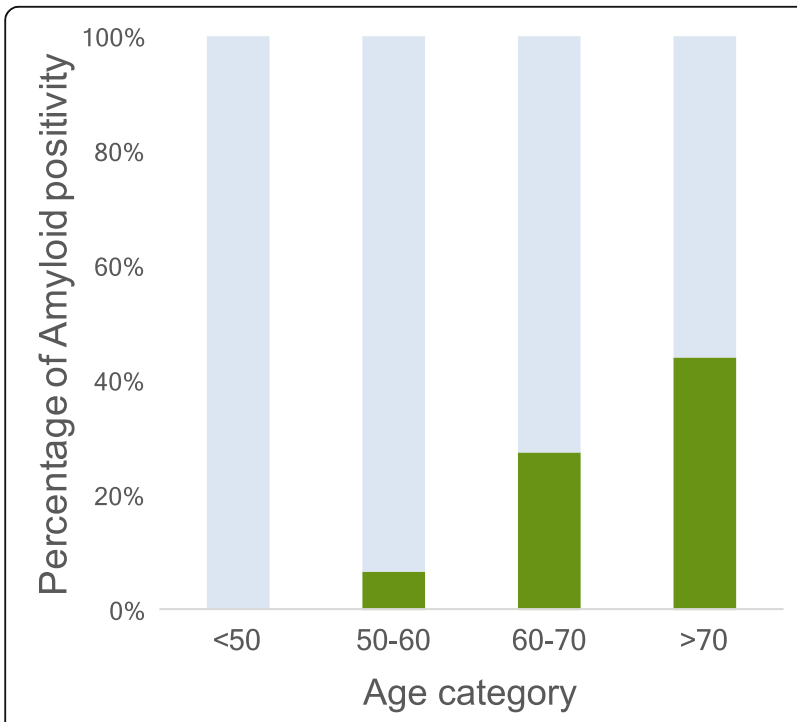

Fig. 3 Percentage of amyloid positivity per decade. Percentage of amyloid positivity per age category in participants with available amyloid status $(n=114)$ which is in line with the literature on the $\mathrm{CCI}$ and objective performance [38]. Although self-report of SCD has been associated with future cognitive decline $[5,8]$, and also has been suggested to be more sensitive for subtle decline than informant report in the very earliest stages of cognitive decline, earlier cross-sectional associations have not been consistent [11,39-41]. This could be a result of the use of different SCD measures [42]. Indeed, we found no significant associations between objective cognition and SCF, which measures cognitive complaints over a shorter period of time and consists of four questions only, in contrast to the observed associations with the CCI.

Cognitive complaints in cognitively normal individuals were previously found to have a broad range of associated symptoms, varying from distress to affective disorders, systemic illnesses, and preclinical AD [11, 12, 15, 16, 39]. In the current paper we evaluated the prevalence of preclinical AD and subthreshold psychiatric features as potential factors associated with the occurrence of SCD [4]. We observed that $25 \%$ of participants with available amyloid status had preclinical AD, and amyloid positivity increased with age. Although we did not make a formal comparison, percentages of amyloid positivity per decade seem somewhat higher in our cohort than in individuals with SCD in a recent large meta-analysis investigating amyloid prevalence in the nondemented elderly [43].

In our sample, $38 \%$ of participants experienced subthreshold psychiatric symptoms on one or more domains. These symptoms were labeled subthreshold since individuals with a clear psychiatric diagnosis, such as major depression, were not included. The group with subthreshold psychiatric symptoms reported more cognitive complaints than the group with preclinical AD. We evaluated six psychiatric features which have been previously associated with cognitive complaints in individuals with SCD, and might provide an alternative explanation for the subjective experience of decline $[15,16,39,41,44]$. On the other hand, several of these psychiatric features, such as depressive symptoms, anxiety, neuroticism, and distress, have also been associated with preclinical AD [45-51], and, indeed, we also saw the co-occurrence of preclinical $A D$ and subthreshold psychiatric symptoms in 8 of 28 cases. We are currently following all participants to study clinical progression in these different groups.

For $43 \%$ of the remaining SCIENCe participants, we found neither preclinical AD nor subthreshold psychiatry. Individuals in the undetermined category had fewer cognitive complaints than the other two categories, both reported by themselves and by the informant. Nonetheless, each of these patients was referred to the memory clinic for evaluation of complaints. In the undetermined category we found a higher prevalence of 


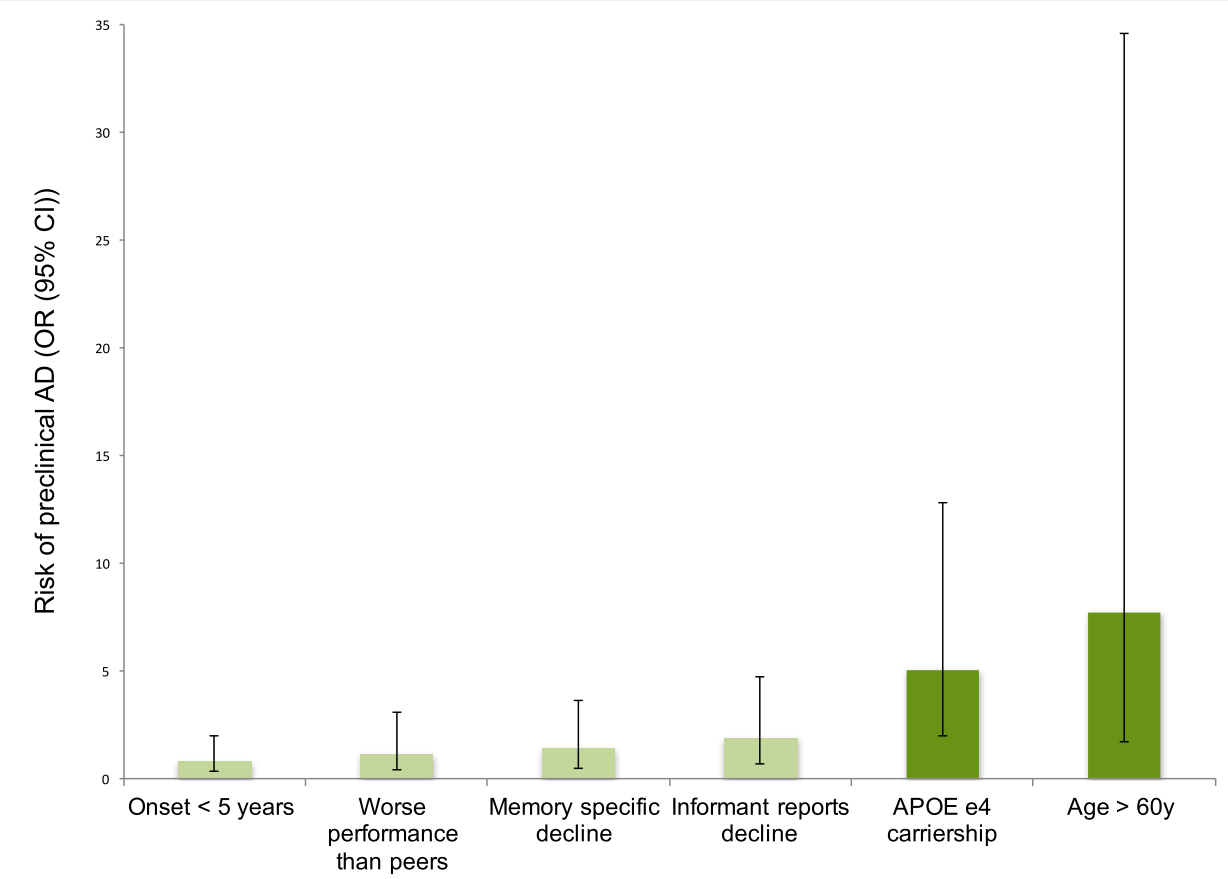

Fig. 4 SCD-plus criteria and risk of preclinical AD. Risk of preclinical AD for each SCD-plus criterion in participants with available amyloid status $(n=114)$. AD Alzheimer's disease, APOE apolipoprotein E (genotype), Cl confidence interval, OR odds ratio

family history of dementia than in the subthreshold psychiatry category, similar to preclinical AD. Perhaps anxiousness related to family history of dementia, rather than the actual experience of cognitive decline, could be a reason to visit the memory clinic for evaluation [52].

To facilitate harmonization of SCD research, the international SCD Working Group (SCD-I) has published a conceptual framework on SCD research, which included the SCD-plus criteria as determinants of preclinical AD [4]. This is the first time the SCD-plus criteria were comprehensively evaluated in a clinical setting. We found that the SCD-plus criteria age $\geq 60$ and APOE e4 carriership were associated with an increased risk of preclinical $A D$, which is in line with the literature $[11,43,53]$. The four other SCD-plus criteria we evaluated were not associated with preclinical $\mathrm{AD}$ in our cohort. There was a trend for an increased risk of preclinical AD when the informant reported significant decline, but results were not significant. The lack of association between informant report and preclinical AD is in contrast with a previous study showing an association between these factors [54]. This contrast could possibly be explained by differences in informant report measurement methods, as well as differences in sample size between the previous study and ours. Since informant report seems to be a better predictor of future cognitive decline than patient report $[7,10,55]$, future longitudinal evaluation of SCIENCe participants and

Table 3 SCD-plus criteria and the risk of preclinical AD in individuals with available amyloid status $(n=114)$

\begin{tabular}{|c|c|c|c|c|c|}
\hline \multirow[t]{2}{*}{ Predictor } & \multirow{2}{*}{$\begin{array}{l}\text { Data availability }(n) \\
\text { in group with known } \\
\text { amyloid status }(n=114)\end{array}$} & \multicolumn{2}{|c|}{ Prevalence of SCD-plus criteria ${ }^{a}$} & \multicolumn{2}{|c|}{ Risk of preclinical $A D^{b}$} \\
\hline & & $\begin{array}{l}\text { Preclinical AD } \\
(n=28)\end{array}$ & $\begin{array}{l}\text { Amyloid negative } \\
(n=86)\end{array}$ & Univariate model & $\begin{array}{l}\text { Multivariate } \\
\text { stepwise model }\end{array}$ \\
\hline Memory specific decline & 94 & $13(59 \%)$ & $37(51 \%)$ & $1.4(0.5-3.6)$ & - \\
\hline Onset $<5$ years & 111 & $12(46 \%)$ & $43(51 \%)$ & $0.8(0.3-2.0)$ & - \\
\hline Age $\geq 60$ years & 114 & $26(93 \%)$ & $54(63 \%)$ & $7.7(1.7-34.6)$ & $3.8(1.7-20.4)$ \\
\hline Experience of worse performance than others & 90 & $13(65 \%)$ & $44(63 \%)$ & $1.1(0.4-3.1)$ & - \\
\hline Informant reports decline & 97 & $15(60 \%)$ & $32(44 \%)$ & $1.9(0.7-4.7)$ & - \\
\hline APOE e4 carriership & 110 & 17 (65\%) & $23(27 \%)$ & $5.0(2.0-12.8)$ & $6.2(1.7-22.2)$ \\
\hline
\end{tabular}

$A D$ Alzheimer's disease, $A P O E$ apolipoprotein $E$ (genotype), $S C D$ subjective cognitive decline

${ }^{a}$ Prevalence of each SCD-plus criterion in individuals with and without preclinical AD, presented as $n(\%)$, within cases with amyloid status available ( $n=114$ )

${ }^{b}$ Risk of preclinical AD separately (univariate models) for each SCD-plus criterion and independent predictors of preclinical AD in a multivariate stepwise model in SCIENCe participants with available amyloid status $(n=114)$, presented as odds ratio ( $95 \%$ confidence interval) 
extension of sample size may reveal further relations. Furthermore, the criteria 'worse performance than others of the same age' and 'memory specific decline' were not associated with an increased risk of preclinical $\mathrm{AD}$, which is in contrast to previous studies indicating both concepts to be associated with preclinical $\mathrm{AD}[11,56]$. We used questions from the CCI and SCF to assess these topics (respectively feeling of worse performance than others (yes/no) and how do you evaluate your memory function compared to 1 year ago (stable/decline)). For these two SCD-plus criteria, differences between results may be caused by methodological variation in SCD measurements, which are known to result in great variation between studies [42]. Criterion 'onset of symptoms within 5 years' did not alter the risk of preclinical $\mathrm{AD}$ in our cohort. To our knowledge this is the first study evaluating the association between onset of symptoms within 5 years and preclinical $\mathrm{AD}$, whereas others evaluated the risk of future cognitive decline in relation to onset of symptoms, without taking into account preclinical AD [57-59].

Limitations of the study include the availability of amyloid status in the cohort for 114 of 151 participants. Because of the availability of amyloid status, participants that are now classified in the subthreshold or undetermined category may have preclinical AD of which we are unaware, since we hierarchically first included participants in the preclinical AD group, followed by categorization of the remaining participants (amyloid status negative or unknown) in the other two groups. Strengths of the study include the highly standardized assessment of a broad range of factors potentially related to SCD, including various biomarkers, as well as repeated collection of blood and CSF for biobanking to be able to evaluate biomarkers longitudinally.

In the light of a disease evolving over decades, longitudinal evaluation seems necessary to assess if, and when, those with and without preclinical AD eventually show progression to MCI or dementia. In SCIENCe we aim to evaluate which factors predict progression, but also which factors are protective of future decline. Discriminating preclinical AD from the 'worried well' seems especially important as anti-amyloid therapies targeting early stages of $\mathrm{AD}$ appear a realistic possibility in the nearby future [60]. Furthermore, assessment of factors other than preclinical AD contributing to SCD may be of importance, since also nonpharmacological interventions seem to be of added value in individuals with SCD [61].

\section{Conclusions}

In summary, this first cross-sectional evaluation of SCIENCe participants revealed that SCD is a heterogeneous group, with subthreshold psychiatric features alongside preclinical $\mathrm{AD}$. We found that subjective report of decline was associated with objective measures. Furthermore, we found a number of SCD-plus criteria to be associated with preclinical AD. Further inclusion and follow-up will address important questions related to SCD.

\section{Additional file}

Additional file 1: Table S1. Standardized tests and questionnaires used in the SCIENCe project. (PDF $323 \mathrm{~kb}$ )

\section{Abbreviations}

Aß: Amyloid-beta; AD: Alzheimer's disease; APOE: Apolipoprotein E (genotype); CCl: Cognitive Change Index; CSF: Cerebrospinal fluid; MCl: Mild cognitive impairment; MMSE: Mini-Mental State Examination; PET: Positron emission tomography; RAVLT: Rey Auditory Verbal Learning Test; sß: Standardized beta; SCD: Subjective cognitive decline; SCF: Subjective Cognitive Functioning; SCIENCe: Subjective Cognitive Impairment Cohort; TMT: Trail Making Test

\section{Acknowledgements}

The authors kindly thank Ellen Dicks for visual rating of MRI scans. The authors acknowledge Arno de Wilde and Wiesje Pelkmans for acquisition of florbetaben scans. The authors are grateful to Emma van den Berg for her contribution to data acquisition.

\section{Funding}

The SCIENCe cohort has been made possible by a generous research grant from the Gieskes-Strijbis Fonds; RERS and SCJV are supported by this research grant from Gieskes-Strijbis Fonds. SAMS is a recipient of JPND-EURO-SCD (grant number JPND_PS_FP-689-019). BMVB is recipient of a Janssen-Stellar grant, and has received research support from the Alzheimer Assistance Foundation, the Center for Translational Molecular Imaging, the Alzheimer Association, De Hersenstichting Nederland, Alzheimer Nederland, and ZonMW. $\left[{ }^{18} \mathrm{~F}\right]$ Florbetaben imaging was made possible by a research grant from Piramal Imaging and ZonMW-Memorabel (ABIDE; project number 70.73305-98-205), in the context of the Dutch Deltaplan Dementia. $\left[{ }^{18} \mathrm{~F}\right]$ Florbetapir imaging was made possible by research support from Avid Radiopharmaceuticals Inc. (Philadelphia, PA, USA). The VUmc Alzheimer Center is supported by Alzheimer Nederland and Stichting VUmc fonds, and the clinical database structure was developed with funding from Stichting Dioraphte. Research of the VUmc Alzheimer Center is part of the neurodegeneration research program of Neuroscience Amsterdam.

\section{Availability of data and materials}

The datasets generated and analyzed during the current study are not publicly available due to local privacy regulations, but are available from the corresponding author on reasonable request.

\section{Authors' contributions}

RERS, SCJV, SAMS, and WMVdF performed statistical analyses, interpreted the data, and/or were major contributors to the manuscript. RERS, SCJV, LMPW, $\mathrm{TT}$, and JMO collected clinical patient data. CET supervised CSF analyses. FB supervised MRI analyses. SCJV, TT, BNMVB, and AAL were involved in acquisition or supervision of PET scans. FHB, NDP, PS, and AD were involved in clinical patient evaluation. All authors read and approved the final manuscript.

\section{Ethics approval and consent to participate}

The local medical ethics committee of the VU University Medical Center approved the study and all patients provide written informed consent for the use of their clinical data and biomaterial in research. All research is conducted in accordance with the Helsinki Declaration of 1975. 


\section{Competing interests}

RERS, SCJV, JMO, TT, LMPW, AD, BNMVB, AAL and FHB report no disclosures. CET serves on the advisory board of Fujirebio and Roche; performed contract research for IBL, Shire, Boehringer, Roche, and Probiodrug; and received lecture fees from Roche and Axon Neurosciences. NDP serves on the advisory board of Boehringer Ingelheim and Probiodrug, and on the DSMB of Abbvie's M15-566 trial; has provided consultancy services for Sanofi, Takeda, and Kyowa Kirin Pharmaceutical Development; receives research support from Alzheimer Nederland (project number WE.03-2012-02); and is CEO and co-owner of the Alzheimer Research Center, Amsterdam, the Netherlands. FB served as a consultant for Bayer-Schering Pharma, BiogenIDEC, TEVA, Merck-Serono, Novartis, Roche, Synthon BV, Jansen Research, and Genzyme; has received speaker's fees from Biogen-IDEC paid to the institution and IXICO; has received research support from the Dutch MS Society and EU grant EU-FP7/H2020; and serves on the editorial boards of Brain, European Radiology, Neurology, Multiple Sclerosis Journal, and Radiology. PS has received grant support for the institution Alzheimer Center, VU University Medical Center from GE Healthcare and MERCK; has received speaker's fees paid to the institution Alzheimer Center, VU University Medical Center, from Lilly, GE Healthcare, and Roche; and serves as editor in chief of Alzheimer's Research and Therapy, but was not involved in the reviewing process. SAMS provided consultancy services in the past 2 years for Nutricia and Takeda; all fees were paid to her institution. WMVdF has received research funding and speaker honorarium from Boehringer Ingelheim; research programs have been funded by ZonMW, NWO, EU-FP7, Alzheimer Nederland, CardioVasculair Onderzoek Nederland, stichting Dioraphte, GieskesStrijbis fonds, Boehringer Ingelheim, Piramal Neuroimaging, Roche BV, Janssen Stellar, and Combinostics; and all funding is paid to her institution.

\section{Publisher's Note}

Springer Nature remains neutral with regard to jurisdictional claims in published maps and institutional affiliations.

\section{Author details}

'Alzheimer Center and Department of Neurology, Amsterdam Neuroscience, Amsterdam University Medical Centers, Vrije Universiteit, De Boelelaan 1118, $1081 \mathrm{HZ}$ Amsterdam, The Netherlands. ${ }^{2}$ Neurochemistry Laboratory, Department of Clinical Chemistry, Amsterdam University Medical Centers, Vrije Universiteit, Amsterdam, The Netherlands. ${ }^{3}$ Department of Old Age Psychiatry, GGZ InGeest, Amsterdam University Medical Centers, Vrije Universiteit, Amsterdam, The Netherlands. ${ }^{4}$ Department of Radiology and Nuclear Medicine, VU University Medical CenterAmsterdam University Medical Centers, Vrije Universiteit, Amsterdam, The Netherlands. ${ }^{5}$ Institutes of Neurology and Healthcare Engineering, UCL, London, UK. ${ }^{6}$ Department of Epidemiology and Biostatistics, Amsterdam University Medical Centers, Vrije Universiteit, Amsterdam, The Netherlands.

\section{Received: 18 December 2017 Accepted: 29 May 2018}

\section{Published online: 07 August 2018}

\section{References}

1. Scheltens P, Blennow K, Breteler MMB, de Strooper B, Frisoni GB, Salloway S, Van der Flier WM. Alzheimer's disease. Lancet. 2016;388:505-17.

2. Jack CR, Knopman DS, Jagust WJ, Petersen RC, Weiner MW, Aisen PS, Shaw LM, Vemuri P, Wiste HJ, Weigand SD, Lesnick TG, Pankratz VS, Donohue MC, Trojanowski JQ. Tracking pathophysiological processes in Alzheimer's disease: an updated hypothetical model of dynamic biomarkers. Lancet Neurol. 2013;12:207-16.

3. Sperling RA, Aisen PS, LA B, Bennett D, Craft S, Fagan AM, Iwatsubo T, Jack CR, Kaye J, Montine TJ, Park DC, Reiman EM, Rowe CC, Siemers E, Stern Y, Yaffe K, Carrillo MC, Thies B, Morrison-Bogorad M, Wagster MV, Phelps CH. Toward defining the preclinical stages of Alzheimer's disease: recommendations from the National Institute on Aging-Alzheimer's Association workgroups on diagnostic guidelines for Alzheimer's disease. Alzheimers Dement. 2011;7:280-92.

4. Jessen F, Amariglio RE, van Boxtel M, Breteler M, Ceccaldi M, Chételat G, Dubois B, Dufouil C, KA E, van der Flier WM, Glodzik L, van Harten AC, de Leon MJ, McHugh P, Mielke MM, Molinuevo JL, Mosconi L, Osorio RS, Perrotin A, Petersen RC, LA R, Rami L, Reisberg B, Rentz DM, Sachdev PS, de la Sayette V, Saykin AJ, Scheltens P, Shulman MB, Slavin MJ, RA S, Stewart R, Uspenskaya O, Vellas B, Visser PJ, Wagner M. A conceptual framework for research on subjective cognitive decline in preclinical Alzheimer's disease. Alzheimers Dement. 2014;10:844-52.

5. Koppara A, Wagner M, Lange C, Ernst A, Wiese B, König H-H, Brettschneider C, Riedel-Heller S, Luppa M, Weyerer S, Werle J, Bickel H, Mösch E, Pentzek M, Fuchs A, Wolfsgruber S, Beauducel A, Scherer M, Maier W, Jessen F. Cognitive performance before and after the onset of subjective cognitive decline in old age. Alzheimer's Dement Diagnosis, Assess Dis Monit. 2015;1:194-205.

6. Rönnlund M, Sundström A, Adolfsson R, Nilsson L-G. Subjective memory impairment in older adults predicts future dementia independent of baseline memory performance: evidence from the Betula prospective cohort study. Alzheimers Dement. 2015;11:1-8.

7. Gifford KA, Liu D, Lu Z, Tripodis Y, Cantwell NG, Palmisano J, Kowall N, Jefferson AL. The source of cognitive complaints predicts diagnostic conversion differentially among nondemented older adults. Alzheimer's Dement J Alzheimer's Assoc. 2014;10:319-27.

8. Buckley RF, Maruff P, Ames D, Bourgeat P, Martins RN, Masters CL, RaineySmith S, Lautenschlager N, Rowe CC, Savage G, Villemagne VL, Ellis KA. Subjective memory decline predicts greater rates of clinical progression in preclinical Alzheimer's disease. Alzheimers Dement. 2016;12:796-804.

9. Jessen F, Wiese B, Bachmann C, Eifflaender-Gorfer S, Haller F, Kolsch H, Luck T, Mosch E, Van Den Bussche H, Wagner M, Wollny A, Zimmerman T, Pentzek M, Riedel-Heller SG, Romberg HP, Weyerer S, Kaduszkiewicz H, Maier W, Bickel H. Prediction of dementia by subjective memory impairment: effects of severity and temporal association with cognitive impairment. Arch Gen Psychiatry. 2010;67:414-22.

10. Slavin MJ, Sachdev PS, Kochan NA, Woolf C, Crawford JD, Giskes K, Reppermund S, Trollor JN, Draper B, Delbaere K, Brodaty H. Predicting cognitive, functional, and diagnostic change over 4 years using baseline subjective cognitive complaints in the Sydney memory and ageing study. Am J Geriatr Psychiatry. 2015;23:906-14.

11. Amariglio RE, Becker AJ, Carmasin J, Wadsworth LP, Lorius N, Sullivan C, Maye JE, Gidicsin C, Pepin LC, Sperling RA, Johnson KA, Rentz DM. Subjective cognitive complaints and amyloid burden in cognitively normal older individuals. Neuropsychologia. 2012;50:2880-6.

12. Van Harten AC, Visser PJ, Pijnenburg YA, Teunissen CE, Blankenstein MA, Scheltens $P$, Van Der Flier WM. Cerebrospinal fluid A $\beta 42$ is the best predictor of clinical progression in patients with subjective complaints. Alzheimers Dement. 2013;9:481-7.

13. Saykin AJ, Wishart HA, Rabin LA, Santulli RB, Flashman LA, West JD, McHugh $\mathrm{TL}$, Mamourian AC. Older adults with cognitive complaints show brain atrophy similar to that of amnestic MCl. Neurology. 2006;67:834-42.

14. Verfaillie SCJ, Tijms B, Versteeg A, Benedictus MR, Bouwman FH, Scheltens P, Barkhof F, Vrenken H, Van Der Flier WM. Thinner temporal and parietal cortex is related to incident clinical progression to dementia in patients with subjective cognitive decline. Alzheimer's Dement. Diagnosis Assess Dis Monit. 2016:5:1-9.

15. Comijs HC, Deeg DJH, Dik MG, Twisk JWR, Jonker C. Memory complaints; the association with psycho-affective and health problems and the role of personality characteristics. A 6-year follow-up study. J Affect Disord. 2002;72: 157-65.

16. Mewton $L$, Sachdev $P$, Anderson $T$, Sunderland M, Andrews G. Demographic, clinical, and lifestyle correlates of subjective memory complaints in the Australian population. Am J Geriatr Psychiatry. 2014;22: 1222-32.

17. Merema MR, Speelman CP, Foster JK, Kaczmarek EA. Neuroticism (not depressive symptoms) predicts memory complaints in some communitydwelling older adults. Am J Geriatr Psychiatry. 2013;21:729-36.

18. Van Der Flier WM, Pijnenburg YAL, Prins N, Lemstra AW, Bouwman FH, Teunissen CE, van Berckel BNM, Stam CJ, Barkhof F, Visser PJ, van Egmond E, Scheltens P. Optimizing patient care and research: the Amsterdam dementia cohort. J Alzheimers Dis. 2014;41:313-27.

19. Risacher SL, Kim S, Nho K, Foroud T, Shen L, Petersen RC, Jack CR, Beckett LA, Aisen PS, Koeppe RA, Jagust WJ, Shaw LM, Trojanowski JQ, Weiner MW, Saykin AJ, Alzheimer's Disease Neuroimaging Initiative (ADNI). APOE effect on Alzheimer's disease biomarkers in older adults with significant memory concern. Alzheimers Dement. 2015;11:1417-29.

20. Aalten P, Ramakers IH, Biessels GJ, de Deyn PP, Koek HL, OldeRikkert MG, Oleksik AM, Richard E, Smits LL, van Swieten JC, Teune LK, van der Lugt A, Barkhof F, Teunissen CE, Rozendaal N, Verhey FR, van der Flier WM. The Dutch Parelsnoer Institute-neurodegenerative diseases; methods, design and baseline results. BMC Neurol. 2014;14:1-8. 
21. Radloff LS. The CES-D scale: a self-report depression scale for research in the general population. Appl Psychol Meas. 1977;1:385-401.

22. Bjelland I, AA D, Haug TT, Neckelmann D. The validity of the hospital anxiety and depression scale. J Psychosom Res. 2002;52:69-77.

23. Terluin B, Van RW, Schaufeli WB, De Haan M. The four-dimensional symptom questionnaire (4DSQ): measuring distress and other mental health problems in a working population. Work Stress. 2004;18:187-207.

24. Luteijn F, Staren J, van Dijk H. Handleiding bij de Nederlandse Persoonlijkheids Vragenlijst (Manual for the Dutch Personality Questionnaire). Lisse: Swets \& Zeitlinger; 1985.

25. Pearlin LI, Schooler C. The structure of coping. J Health Soc Behav. 1978;19: 2-21.

26. Brooks R, The EuroQol Group. EuroQol: the current state of play. Health Policy (New York). 1996;37:53-72.

27. Folstein M. "Mini-mental state". A practical method for grading the cognitive state of patients for the clinician. J Psychiatr Res. 1975;12:189-98.

28. Rey A. L'examen clinique en psychologi (The clinical examination in psychology). 2nd ed. Paris: Presses Universitaries De France; 1964.

29. Reitan RM. Validity of the trail making test as indicator of organic brain damage. Percept Mot Skills. 1958;8:271-6.

30. Smith SM, Zhang Y, Jenkinson M, Chen J, Matthews PM, Federico A, De SN. Accurate, robust, and automated longitudinal and cross-sectional brain change analysis. Neuroimage. 2002:17:479-89.

31. Popescu V, Battaglini M, Hoogstrate WS, Verfaillie SCJ, Sluimer IC, van Schijndel RA, van Dijk BW, Cover KS, Knol DL, Jenkinson M, Barkhof F, de Stefano N, Vrenken H. Optimizing parameter choice for FSL-brain extraction tool (BET) on 3D T1 images in multiple sclerosis. Neuroimage. 2012;61:1484-94.

32. Del Campo M, Mollenhauer B, Bertolotto A, Engelborghs S, Hampel H, Simonsen AH, Kapaki E, Kruse N, Le Bastard N, Lehmann S, Molinuevo JL, Parnetti L, Perret-Liaudet A, Saez-Valero J, Saka E, Urbina A, Van Mechelen E, Verbeek MM, Visser PJ, Teunissen CE. Recommendations to standardize preanalytical confounding factors in Alzheimer's and Parkinson's disease cerebrospinal fluid biomarkers: an update. Biomark Med. 2012;6:419-30.

33. Teunissen $C E$, Petzold A, Bennett JL, Berven FS, Brundin L, Comabella M, Franciotta D, Frederiksen JL, Fleming JO, Furlan R, Hintzen RQ, Hughes SG, Johnson MH, Krasulova E, Kuhle J, Magnone MC, Rajda C, Rejdak K, Schmidt HK, van Pesch V, Waubant E, Wolf C, Giovannoni G, Hemmer B, Tumani H, Deisenhammer $F$. A consensus protocol for the standardization of cerebrospinal fluid collection and biobanking. Neurology. 2009;73:1914-22.

34. Mulder $C, N A$ V, van der Flier WM, Bouwman FH, Kok A, van Elk EJ, Scheltens P, MA B. Amyloid-beta(1-42), total tau, and phosphorylated tau as cerebrospinal fluid biomarkers for the diagnosis of Alzheimer disease. Clin Chem. 2010;56:248-53.

35. Zwan $M$, van Harten A, Ossenkoppele R, Bouwman F, Teunissen $C$, Adriaanse S, Lammertsma A, Scheltens P, van Berckel B, van der Flier W. Concordance between cerebrospinal fluid biomarkers and [11C]PIB PET in a memory clinic cohort. J Alzheimers Dis. 2014;41:801-7.

36. Cooper C, Bebbington P, Lindesay J, Meltzer H, McManus S, Jenkins R, Livingston $\mathrm{G}$. The meaning of reporting forgetfulness the meaning of reporting forgetfulness: a cross-sectional study of adults in the English 2007 adult psychiatric morbidity survey. Age Ageing. 2011;40:711-7.

37. Maki Y, Yamaguchi T, Yamagami T, Murai T, Hachisuka K, Miyamae F, Ito K, Awata S, Ura C, Takahashi R, Yamaguchi H. The impact of subjective memory complaints on quality of life in community-dwelling older adults. Psychogeriatrics. 2014;14:175-81.

38. Rattanabannakit C, Risacher SL, Gao S, Lane KA, Brown SA, McDonald BC, Unverzagt FW, Apostolova LG, Saykin AJ, Farlow MR. The cognitive change index as a measure of self and informant perception of cognitive decline: relation to neuropsychological tests. J Alzheimers Dis. 2016;51:1145-55.

39. Buckley R, Saling MM, Ames D, Rowe CC, Lautenschlager NT, Macaulay SL, Martins RN, Masters CL, O'Meara T, Savage G, Szoeke C, Villemagne VL, KA E. Factors affecting subjective memory complaints in the AIBL aging study: biomarkers, memory, affect, and age. Int Psychogeriatr. 2013;25:1307-15.

40. Amariglio RE, Townsend MK, Grodstein F, Sperling RA, Rentz DM. Specific subjective memory complaints in older persons may indicate poor cognitive function. J Am Geriatr Soc. 2011;59:1612-7.

41. Snitz BE, Morrow LA, Rodriguez EG, Huber KA, Saxton JA. Subjective memory complaints and concurrent memory performance in older patients of primary care providers. J Int Neuropsychol Soc. 2008;14:1004-13.

42. Rabin LA, Smart CM, Crane PK, Amariglio RE, Berman LM, Boada M, Buckley RF, Chételat $G$, Dubois B, Ellis KA, Gifford KA, Jefferson AL, Jessen F, Katz MJ,
Lipton RB, Luck T, Maruff P, Mielke MM, Molinuevo JL, Naeem F, Perrotin A, Petersen RC, Rami L, Reisberg B, Rentz DM, Riedel-Heller SG, Risacher SL Rodriguez O, Sachdev PS, Saykin AJ, Slavin MJ, Snitz BE, Sperling RA, Tandetnik C, Van Der Flier WM, Wagner M, Wolfsgruber S, Sikkes SAM. Subjective cognitive decline in older adults: an overview of self-report measures used across 19 international research studies. J Alzheimers Dis. 2015;48(suppl 1):S63-86.

43. Jansen WJ, Ossenkoppele R, Knol DL, Tijms BM, Scheltens P, Verhey FRJ, Visser PJ, Aalten P, Aarsland D, Alcolea D, Alexander M, Almdahl IS, Arnold SE, Baldeiras I, Barthel H, van Berckel BNM, Bibeau K, Blennow K, Brooks DJ, van Buchem MA, Camus V, Cavedo E, Chen K, Chetelat G, Cohen AD, Drzezga A, Engelborghs S, Fagan AM, Fladby T, Fleisher AS, van der Flier WM, Ford L, Förster S, Fortea J, Foskett N, Frederiksen KS, Freund-Levi Y, Frisoni GB, Froelich L, Gabryelewicz T, Gill KD, Gkatzima O, Gómez-Tortosa E, Gordon MF, Grimmer T, Hampel H, Hausner L, Hellwig S, Herukka S-K, Hildebrandt H, Ishihara L, Ivanoiu A, Jagust WJ, Johannsen P, Kandimalla R, Kapaki E, Klimkowicz-Mrowiec A, Klunk WE, Köhler S, Koglin N, Kornhuber J, Kramberger MG, Van Laere K, Landau SM, Lee DY, de Leon M, Lisetti V, Lleó A, Madsen K, Maier W, Marcusson J, Mattsson N, de Mendonça A, Meulenbroek O, Meyer PT, Mintun MA, Mok V, Molinuevo JL, Møllergård HM, Morris JC, Mroczko B, Van der Mussele S, Na DL, Newberg A, Nordberg A, Nordlund A, Novak GP, Paraskevas GP, Parnetti L, Perera G, Peters O, Popp J, Prabhakar S, Rabinovici GD, IHGB R, Rami L, Resende de Oliveira C, Rinne JO, Rodrique KM, Rodríquez-Rodríguez E, Roe CM, Rot U, Rowe CC, Rüther E, Sabri O, Sanchez-Juan P, Santana I, Sarazin M, Schröder J, Schütte C, Seo SW, Soetewey F, Soininen H, Spiru L, Struyfs H, Teunissen CE, Tsolaki $M$, Vandenberghe R, Verbeek MM, Villemagne VL, SJB V, van Waalwijk van Doorn LC, Waldemar G, Wallin A, Wallin ÅK, Wiltfang J, Wolk DA, Zboch M, Zetterberg $\mathrm{H}$. Prevalence of cerebral amyloid pathology in persons without dementia. JAMA. 2015;313:1924.

44. Van Der Flier WM, van Buchem MA, Weverling-Rijnsburger AWE, Mutsaers ER, Bollen ELEM, Admiraal-Behloul F, Westendorp RGJ, Middelkoop HAM. Memory complaints in patients with normal cognition are associated with smaller hippocampal volumes. J Neurol. 2004;251:671-5.

45. Babulal GM, Ghoshal N, Head D, Vernon EK, Holtzman DM, Benzinger TLS, Fagan AM, Morris JC, Roe CM. Mood changes in cognitively normal older adults are linked to Alzheimer disease biomarker levels. Am J Geriatr Psychiatry. 2016;24:1095-104.

46. von Gunten A, Fox NC, Cipolotti L, Ron MA. A volumetric study of hippocampus and amygdala in depressed patients with subjective memory problems. J Neuropsychiatry Clin Neurosci. 2000;12:493-8.

47. Barnes DE, Yaffe K, Byers AL, McCormick M, Schaefer C, Whitmer RA. Midlife vs late-life depressive symptoms and risk of dementia. Arch Gen Psychiatry. 2012;69:493-8.

48. Snitz BE, Weissfeld LA, Cohen AD, Lopez OL, Nebes RD, Aizenstein HJ, McDade E, Price JC, Mathis CA, Klunk WE. Subjective cognitive complaints, personality and brain amyloid-beta in cognitively normal older adults. Am J Geriatr Psychiatry. 2015;23:985-93.

49. Terracciano A, Sutin AR, An Y, O'Brien RJ, Ferrucci L, Zonderman AB, Resnick SM. Personality and risk of Alzheimer's disease: new data and meta-analysis. Alzheimers Dement. 2014;10:179-86.

50. Johansson L, Guo X, Duberstein PR, Hallstrom T, Waern M, Ostling S, Skoog I. Midlife personality and risk of Alzheimer disease and distress: a 38-year follow-up. Neurology. 2014;83:1538-44.

51. Pietrzak RH, Lim $Y$, Neumeister A, Ames $D$, Ellis KA, Harrington $K$, Lautenschlager NT, Restrepo C, Martins RN, Masters CL, Villemagne VL, Rowe CC, Maruff P. Amyloid- $\beta$, anxiety, and cognitive decline in preclinical Alzheimer disease: a multicenter, prospective cohort study. JAMA Psychiatry. 2015;72:284-91.

52. Ramakers IHGB, Visser PJ, Bittermann AJN, Ponds RWHM, Van BMPJ, Verhey FRJ. Characteristics of help-seeking behaviour in subjects with subjective memory complaints at a memory clinic: a case-control study. Int J Geriatr Psychiatry. 2009;24:190-6.

53. Zwan MD, Villemagne VL, Dore V, Buckley R, Bourgeat $P$, Veljanoski $R$, Salvado O, Williams R, Margison L, Rembach A, Macaulay SL, Martins R, Ames D, van der Flier WM, Ellis KA, Scheltens P, Masters CL, Rowe CC. Subjective memory complaints in APOE e4 carriers are associated with high amyloid-beta burden. J Alzheimers Dis. 2016;49:1115-22.

54. Valech N, Mollica MA, Olives J, Tort A, Fortea J, Lleo A, Belen S-S, Molinuevo $J$, Rami L. Informants' perception of subjective cognitive decline helps to discriminate preclinical Alzheimer's disease from normal aging. J Alzheimers Dis. 2015;48:587-98. 
55. Rueda AD, Lau KM, Saito N, Harvey D, Risacher SL, Aisen PS, Petersen RC, Saykin AJ, Farias ST. Self-rated and informant-rated everyday function in comparison to objective markers of Alzheimer's disease. Alzheimers Dement. 2015:11:1080-9.

56. Perrotin A, Mormino EC, Madison CM, Hayenga AO, Jagust WJ. Subjective cognition and amyloid deposition imaging. Arch Neurol. 2012;62:223-9.

57. Dufouil C, Fuhrer R, Alpe A. Subjective cognitive complaints and cognitive decline: consequence or predictor? The epidemiology of vascular aging study. J Am Geriatr Soc. 2005;53:616-21.

58. Treves TA, Verchovsky R, Klimovitzky S, Korczyn AD. Incidence of dementia in patients with subjective memory complaints. Int Psychogeriatrics. 2005; 17:265-73.

59. Chary E, Amieva H, Peres K, Orgogozo J, Dartigues JF, Jacamin-Gadda H. Short- versus long-term prediction of dementia among subjects with low and high educational levels. Alzheimers Dement. 2013;9:562-71.

60. Molinuevo JL, Rabin LA, Amariglio R, Buckley R, Dubois B, Ellis KA, Ewers M, Hampel H, Kloppel S, Rami L, Reisberg B, Saykin AJ, Sikkes S, Smart CM, Snitz $B E$, Sperling R, van der Flier WM, Wagner M, Jessen F. Implementation of subjective cognitive decline criteria in research studies. Alzheimers Dement. 2017;13(3):296-311.

61. Smart CM, Karr JE, Areshenkoff CN, Rabin LA, Hudon C, Gates N, Ali Jl, Arenaza-urquijo EM. Non-pharmacologic interventions for older adults with subjective cognitive decline: systematic review, meta-analysis, and preliminary recommendations. Neuropsychol Rev. 2017;27(3):245-57.

Ready to submit your research? Choose BMC and benefit from:

- fast, convenient online submission

- thorough peer review by experienced researchers in your field

- rapid publication on acceptance

- support for research data, including large and complex data types

- gold Open Access which fosters wider collaboration and increased citations

- maximum visibility for your research: over $100 \mathrm{M}$ website views per year

At BMC, research is always in progress.

Learn more biomedcentral.com/submissions 